\title{
Pembelajaran Kooperatif Tipe Jigsaw dalam Pembelajaran Matematika di Sekolah Dasar
}

\author{
Rien Anitra ${ }^{1)}$ \\ 1) Pendidikan Guru Sekolah Dasar, STKIP Singkawang, Singkawang, Indonesia \\ E-mail:anitrarien@gmail.com
}

\begin{abstract}
Pembelajaran matematika di sekolah dasar memerlukan model pembelajaran yang tepat agar hasil belajar siswa maksimal. Penulisan artikel ini menggunakan studi literatur atau literature riview dengan menganalisis beberapa kajian yang berkaitan dengan topik pembahasan, yaitu: pembelajaran kooperatif, model pembelajaran jigsaw, dan matematika. Pembelajaran kooperatif merupakan pembelajaran dalam suatu kelompok kecil yang heterogen untuk saling bekerja sama, saling menyumbang pikiran dalam mengkonstruk konsep dan memecahkan masalah dengan tanggung jawab dan tujuan bersama serta saling ketergantungan positif sekaligus berlatih berinteraksi, komunikasi, dan sosialisasi. Pembelajaran kooperatif tipe jigsaw terdapat kelompok asal yang heterogen dan kemudian dibentuk kelompok ahli untuk menjadikan siswa-siswa ahli suatu topik yang ditugaskan kemudian saling berbagi informasi kepada teman-teman yang membahas topik berbeda di dalam kelompok asalnya. Berdasarkan kajian terhadap hasil penelitian mengenai pembelajaran kooperatif tipe jigsaw, ditemukan bahwa pembelajaran kooperatif tipe jigsaw mempengaruhi hasil belajar dan prestasi belajar matematika siswa. Kemudian terungkap pula bahwa pembelajaran kooperatif tipe jigsaw dapat meningkatkan hasil belajar dan prestasi belajar matematika siswa.
\end{abstract}

Keywords: kooperatif, jigsaw, matematika

\begin{abstract}
Learning mathematics in elementary schools requires an appropriate learning model so that student learning outcomes are maximum. Writing this article using a literature study or literature review by analyzing several studies related to the topic of discussion, namely: cooperative learning, jigsaw learning models, and mathematics. Cooperative learning is learning in a small, heterogeneous group to work together, contributing thoughts in constructing concepts and solving problems with shared responsibility and goals as well as positive interdependence as well as practicing interaction, communication and socialization. Jigsaw-type cooperative learning has a heterogeneous origin group and then expert groups are formed to make expert students an assigned topic and then share information with friends who discuss different topics in their original group. Based on a study of the results of research on the type of jigsaw cooperative learning, it was found that the jigsaw type of cooperative learning affects student learning outcomes and mathematics achievement. Then it was also revealed that the type of jigsaw cooperative learning can improve student learning outcomes and mathematics learning achievement.
\end{abstract}

Keywords: cooperative, jigsaw, math

\section{PENDAHULUAN}

Pembelajaran matematika merupakan salah satu pembelajaran wajib di sekolah dasar. Pada mata pelajaran matematika, terdapat materi-materi pelajaran yang saling bekaitan satu sama lain, dan juga sebagai mata pelajaran yang berkaitan dengan mata pelajaran lainnya di sekolah dasar. Hal inilah yang menunjukkan bahwa matematika tidak sekedar belajar cara menghitung, tetapi juga dapat diterapkan pada mata pelajaran lainnya.

Pentingnya pembelajaran matematika di sekolah dasar ini belum didukung oleh hasil belajar matematika siswa yang maksimal. Hal ini ditunjukkan oleh hasil penelitian Lutfiyah \& Setyawan [1], bahwa siswa kurang dan sulit menerima materi, pelaksanaan metode pembelajaran yang tidak sesuai dengan sintaksnya. Hasil test membuktikan bahwa sekitar 25 siswa ada siswa yang tidak tuntas yaitu 14 dalam 
pembelajaran matematika untuk mencapai KKM, sehingga disimpulkan bahwa metode pembelajaran yang diterapkan pada pembelajaran matematika masih kurang sesuai yang mengakibatkan hasil belajar siswa tidak tercapai secara maksimal.

Pembelajaran matematika di sekolah dasar memerlukan model pembelajaran yang tepat agar hasil belajar siswa maksimal. Joyce \& Weil [2] mendefinisikan model pembelajaran sebagai kerangka konseptual yang digunakan sebagai pedoman dalam melakukan pembelajaran. Salah satu model pembelajaran yang dapat diterapkan pada pembelajaran matematika SD adalah model pembelajaran jigsaw.

Model pembelajaran jigsaw ini merupakan salah satu dari pembelajaran kooperatif yang melibatkan siswa secara aktif di dalam pembelajaran dan melatih siswa bekerja sama di dalam sebuah kelompok. Pada prosesnya, terdapat kelompok asal yang heterogen dan kemudian dibentuk kelompok ahli untuk menjadikan siswa-siswa ahli suatu topik yang ditugaskan kemudian saling berbagi informasi kepada teman-teman yang membahas topik berbeda di dalam kelompok asalnya. Dengan demikian, langkah-langkah model pembelajaran jigsaw dapat diterapkan pada pembelajaran matematika SD.

Berdasarkan hasil penelitian Yunus [3], pembelajaran Jigsaw dapat meningkatkan hasil belajar siswa pada pelajaran matematika. Selain itu, hasil penelitian Setiyono, Muslim, \& Irianto [4] juga menunjukkan bahwa pembelajaran jigsaw dapat meningkatkan hasil belajar matematika siswa.

Uraian di atas menunjukkan pentingnya menerapkan model pembelajaran yang tepat untuk pembelajaran matematika di SD. Maka dari itu, untuk meningkatkan hasil belajar matematika siswa dapat diterapkan model pembelajaran jigsaw. Dengan demikian, diharapkan menjadi salah satu alternatif bagi guru agar dapat melaksanakan proses pembelajaran matematika secara efektif dan mencapai tujuan pembelajaran.

\section{METODE}

Artikel ini menggunakan studi literatur atau literature riview dengan menganalisis beberapa kajian yang berkaitan dengan topik pembahasan, yaitu: pembelajaran kooperatif, model pembelajaran jigsaw, dan matematika. Sumber-sumber rujukan yang menjadi pokok bahasan bersumber dari buku, artikel dari jurnal, prosiding dan lainnya. Hal tersebut dimaksudkan untuk meninjau pembelajaran jigsaw sebagai salah satu model pembelajaran matematika di sekolah dasar.

\section{HASIL DAN PEMBAHASAN}

\section{A. Pembelajaran Kooperatif Tipe Jigsaw}

Pembelajaran kooperatif menurut Hardini dan Dewi [5] merupakan salah satu model pembelajaran kelompok yang memiliki aturan-aturan tertentu. Pembelajaran kelompok yang dilakukan siswa betujuan untuk melatih siswa belajar secara mandiri dengan menentukan cara belajaranya sendiri di dalam kelompok. Walaupun demikian, pembelajaran kelompok tetap memiliki aturan-aturan agar bisa bekerja sama di dalam tim.
Slavin dalam Laboro [6] mendefinisikan belajar kooperatif sebagai berikut "cooperative learning methods share the ideas that students work together to learn and are responsible for their teammates learning as wel as their own". Definisi ini mengandung pengertian bahwa dalam belajar kooperatif siswa belajar bersama, saling menyumbang pemikiran dan bertanggung jawab terhadap pencapaian hasil belajar secara individu maupun kelompok. Proses pembelajaran kelompok ini dapat melatih siswa belajar bertukar pemikiran, ide, dan pendapat.

Menurut Brahim [7], pembelajaran kooperatif sesuai dengan fitrah manusia sebagai makhluk sosial yang penuh ketergantungan dengan orang lain, mempunyai tujuan dan tanggung jawab bersama, pembagian tugas, dan rasa senasib. Dengan demikian pada pembelajaran kooperatif siswa dilatih dan dibiasakan untuk saling berbagi (sharing) pengetahuan, pengalaman, tugas, dan tanggung jawab serta saling membantu dan berlatih berinteraksi, komunikasi-sosialisasi karena kooperatif adalah miniature dari hidup bermasyarakat, dan belajar menyadari kekurangan dan kelebihan masingmasing.

Pembelajaran kooperatif merupakan kegiatan pembelajaran dengan cara berkelompok untuk bekerja sama saling membantu mengkonstruk konsep, menyelesaikan persoalan, atau inkuiri. Menurut teori dan pengalaman agar kelompok kohesif (kompak-partisipatif), tiap anggota kelompok terdiri dari 4-5 orang, siswa heterogen (kemampuan, gender, karakter), ada kontrol dan fasilitasi, dan meminta tanggung jawab hasil kelompok berupa laporan atau presentasi.

Dari beberapa uraian di atas, dapat disimpulkan bahwa pembelajaran kooperatif adalah pembelajaran dalam suatu kelompok kecil yang heterogen untuk saling bekerja sama, saling menyumbang pikiran dalam mengkonstruk konsep dan memecahkan masalah dengan tanggung jawab dan tujuan bersama serta saling ketergantungan positif sekaligus berlatih berinteraksi, komunikasi, dan sosialisasi.

Metode pembelajaran kooperatif memiliki banyak tipe, salah satunya yaitu jigsaw. Pada pembelajaran Jigsaw, siswa bekerja bersama dalam kelompok-kelompok kecil di mana mereka harus saling membantu [8]. Tiap-tiap anggota kelompok menjadi "ahli" dalam subjek persoalannya dan oleh karena itu memiliki informasi penting untuk berkontribusi kepada teman sekelas. Saling bekerjasama dan saling percaya menjadi berharga dan perlu untuk pencapaian akademis. Menurut Nurhadi dalam Thoboroni dan Mustofa [9], metode jigsaw dikembangkan oleh Aronson dan kawan-kawannya dari Universitas texas dan kemudian di adaptasi oleh Slavin dan kawan-kawannya.

Pada tahun 1972, di Austin, Texas, sekelompok administratur, guru, dan peneliti membentuk proyek berjangka enam tahun untuk menemukan cara menyusun ulang proses pengajaran dan pembelajaran untuk mengembangkan persamaan dalam partisipasi dan hasil bagi semua anak di kelas. Yang menjadi inti pekerjaan mereka adalah keinginan untuk mengurangi etos kompetisi di kelas yang menciptakan hadiah-hadiah ekonomi palsu di mana beberapa siswa "menang" dan banyak yang "kalah". Kelompok itu menguji coba untuk mencipatakan dan meneliti sebuah proses yang 
bisa berguna agar siswa saling memperlakukan siswa yang lain sebagai sumber belajar. Pertama, mereka menyusun proses pembelajaran yang terstruktur sehingga persaingan individual tidak sejalan dengan keberhasilan, dan kedua, mereka menciptakan keyakinan bahwa keberhasilan hanya bisa diperoleh jika para siswa bekerjasama. Sejak saat itu, pendekatan Jigsaw berkembang dan menyebar ke dalam kelas-kelas dan ke dalam aktivitas pengembangan-staf di banyak dunia kerja di seluruh dunia.

Gagasan utama persamaan proses kelompok rekonstruksi sebagai "Jigsaw" muncul dari metafora penggabungan potongan teka-teki untuk mencipatakan gambar yang utuh [8]. Sejak Aronson dan timnya pertama kali menerbitkan pendekatan mereka pada tahun 1978, beberapa versi telah muncul. Meskipun pendekatan Jigsaw sangat mudah diterapkan dengan variasi tidak terbatas, ada empat tahap dasar di dalam prosesnya.

\section{Tahap 1: Pendahuluan}

Guru menyusun kelas menjadi kelompok "inti” heterogen. Selanjutnya guru memberikan tema, teks, informasi, atau materi-materi kepada kelas itu dan membantu siswa memahami mengapa mereka mempelajari tema itu, bagaimana menyesuaikan tema tema itu dengan apa yang telah mereka kerjakan sebelumnya, dan apa yang akan mereka pelajari selanjutnya. Dalam tahap ini, yang penting adalah bahwa siswa menjadi tertarik dengan apa yang sedang mereka. Guru menjelaskan bahwa hasil belajar siswa akan dinilai seluruhnya.

\section{Tahap 2: Eksplorasi Terfokus}

Siswa dikelompokkan kembali untuk membentuk kelompok focus. Para anggota kelompok fokus bekerja bersama-sama untuk mempelajari tema tertentu.

\section{Tahap 3: Melaporkan dan Menyusun Ulang}

Siswa kembali ke kelompok inti mereka untuk mengambil giliran menjelaskan gagasan yang dihasilkan dalam kelompok fokus. Selama tahap pelaporan, para anggota kelompok didorong mengajukan pertanyaan dan membicarakan gagasan itu secara mendalam.

\section{Tahap 4: Integrasi dan Evaluasi}

Guru bisa merancang aktivitas individu, kelompok-kecil atau seluruh kelas di mana para siswa bisa secara aktif menyatukan hasil belajar mereka. Misalnya, siswa bisa melakukan tugas demonstrasi dalam kelompok inti mereka. Guru akan mengajukan pertanyaan untuk membantu siswa berpikir ulang tentang bagaimana mereka bekerja bersamasama dan apakah mereka bisa bekerja dengan cara yang sama atau berbeda di masa-masa mendatang ketika mereka bekerja bersama.

Siswa bekerja dalam "kelompok inti" mereka, tetapi masuk lagi ke dalam "kelompok ahli", yang masing-masing darinya menguasai tugas pembelajaran yang berbeda. Semua penugasan merupakan bagian penting dari unit kerja yang sama. Setelah kelompok-kelompok ahli menguasai bagian mereka atas unit itu, siswa kembali ke kelompok-kelompok inti mereka dan saling memberitahu pengetahuan baru yang telah mereka peroleh. Aktivitas itu berakhir dengan tahap dengan setiap siswa yang harus menggunakan pengetahuan atas seluruh unit itu. Ini bisa diselesaikan dengan menyelenggarakan tes individual atau dengan diskusi seluruh kelas atau bermain person di mana siswa secara sendirisendiri diminta menunjukkan "kemahiran" mereka.

Sejalan dengan hal di atas, langkah-langkah pembelajaran kooperatif tipe jigsaw menurut Lie [10] adalah sebagai berikut:

1. Pengajar membagi bahan pelajaran yang akan diberikan menjadi empat bagian.

2. Sebelum pelajaran diberikan, pengajar memberikan pengenalan mengenai topic yang akan dibahas dalam bahan pelajaran untuk hari ini. Pengajar bisa menuliskan topik di papan tulis dan menanyakan apa yang siswa ketahui mangenai topic tersebut.

3. Siswa dibagi dalam kelompok berempat.

4. Bagian pertama bahan diberikan kepada siswa yang pertama, sedangkan siswa yang kedua menerima bagian yang kedua. Demikian seterusnya.

5. Kemudian, siswa disuruh membaca/mengerjakan bagian mereka masing-masing.

6. Setelah selesai, siswa saling berbagi mengenai bagian yang dibaca/dikerjakan masing-masing.

7. Khusus untuk kegiatan membaca, kemudian pengajar membagikan bagian cerita yang belum terbaca kepada masing-masing siswa. Siswa membaca bagian tersebut.

8. Kegiatan ini bisa diakhiri dengan diskusi mengenai topik dalam bahan pelajaran hari itu. Diskusi bisa dilakukan antara pasangan atau dengan seluruh kelas.

Menurut Rusman [11] kegiatan yang dilakukan dalam pembelajaran tipe jigsaw adalah:

1. Melakukan membaca untuk menggali informasi. Siswa memperoleh topik-topik permasalahan untuk dibaca, sehingga mendapatkan informasi dari permaslahan tersebut.

2. Diskusi kelompok ahli. Siswa yang telah mendapatkan topik permasalahan yang sama bertemu dalam satu kelompok atau kita sebut dengan kelompok ahli untuk membicarakan topik permasalahan tersebut.

3. Laporan kelompok. Kelompok hali kembali ke kelompok asal dan menjelaskan hasil yang didapat dari diskusi tim ahli.

4. Kuis dilakukan mencakup semua topik permasalahan yang dibicarakan tadi

5. Perhitungan skor kelompok dan menentukan penghargaan kelompok.

Menurut Sharan [8], jigsaw merupakan struktur yang bisa digunakan untuk pemecahan masalah kooperatif. Berikut ini disajikan panduan untuk melakukan pemecahan masalah dengan menggunakan Jigsaw. 
1. Divisi tugas: Tugas atau potongan materi teks atau masalah dibagi-bagi ke dalam beberapa bagian komponen (atau tema).

2. Kelompok inti: Setiap anggota kelompok diberi satu tema agar ia bisa menjadi ahlinya.

3. Kelompok ahli: Para siswa yang mendapatkan tema sama berkumpul dalam kelompok ahli untuk membahas tema, menguasainya dan merencanakan bagaimana mengajarkannya.

4. Kelompok inti: Para siswa kembali ke kelompok asli mereka dan memberitahukan apa yang telah mereka pelajari kepada anggota kelompok mereka.

\section{B. Penggunaan Pembelajaran Kooperatif Tipe Jigsaw pada Pembelajaran Matematika Sekolah Dasar}

Pembelajaran matematika di sekolah dasar perlu menerapkan model pembelajaran yang tepat agar dapat meningkatkan hasil belajar dan prestasi siswa. Salah satunya adalah pembelajaran kooperatif tipe jigsaw. Penelitian mengenai pembelajaran kooperatif tipe jigsaw pada pembelajaran matematika di sekolah dasar sudah banyak dilakukan.

Seperti hasil penelitian Suparni [12] yang menunjukkan bahwa terdapat pengaruh signifikan pada penerapan model pembelajaran kooperatif tipe jigsaw terhadap hasil belajar matematika siswa kelas V SD. Hasil penelitian Hamna \& BK [13] juga memaparkan bahwa pelaksanaan model pembelajaran kooperatif tipe Jigsaw berpengaruh secara positif dan signifikan terhadap hasil belajar matematika siswa kelas V SD. Kemudian didukung oleh hasil penelitian Nurfitriyanti [14] yang menunjukkan terdapat pengaruh metode pembelajaran kooperatif tipe Jigsaw terhadap pembelajaran matematika.

Selain itu, hasil penelitian Handayani [15] memaparkan bahwa pembelajaran kooperatif tipe jigsaw memberikan pengaruh yang signifikan terhadap kemampuan berpikir kritis matematis siswa. Hal ini menunjukkan bahwa penerapan pembelajaran kooperatif tipe jigsaw memberikan dampak positif pada pembelajaran matematika di sekolah dasar. Maka dari itu, guru dapat menerapkan pembelajaran kooperatif tipe jigsaw apabila ingin meningkatkan hasil belajar dan prestasi matematika siswa sekolah dasar.

Sebagaimana ditunjukkan oleh hasil penelitian Marta [16] yang mengungkapkan bahwa melalui pembelajaran kooperatif tipe jigsaw dapat meningkatkan hasil belajar matematika siswa pada kelas V SD. Didukung pula oleh hasil penelitian penelitian Suryani [17] yang menunjukkan bahwa melalui pembelajaran kooperatif tipe Jigsaw dapat meningkatkan hasil belajar matematika siswa pada kelas VI SD. Hal tersebut menunjukkan bahwa penerapan pembelajaran kooperatif tipe jigsaw dengan langkah-langkah yang tepat dalam proses pembelajaran matematika dapat meningkatkan hasil belajar matematika siswa.

Materi pembelajaran matematika sekolah dasar terdiri dari berbagai konsep yang dapat diterapkan dalam pemecahan masalah sehari-sehari. Penerapan pembelajaran kooperatif tipe jigsaw memberikan kesempatan siswa untuk terlibat aktif dalam diskusi dengan kelompoknya untuk membahas konsep yang baru dipelajari dan memecahkan masalah. Seperti hasil penelitian Ragindo [18] yang menunjukkan bahwa model pembelajaran koopertif tipe jigsaw pada pembelajaran matematika khususnya pada materi perkalian bilangan tiga angka dan pembagian bilangan tiga angka dapat meningkatkan hasil belajar siswa kelas III SD. Didukung pula oleh hasil penelitian Ismayani [19] yang mengungkapkan terjadi peningkatan hasil belajar matematika materi bangun ruang model pembelajaran kooperatif tipe jigsaw.

Peningkatan prestasi belajar matematika juga terjadi setelah diterapkannya pembelajaran kooperatif tipe jigsaw. Sebagaimana hasil penelitian Suartini [20] yang memaparkan bahwa model pembelajaran jigsaw dapat meningkatkan prestasi belajar matematika siswa kelas III SD. Hasil penelitian Suryani [21] juga menunjukkan bahwa metode kooperatif tipe jigsaw dapat meningkatkan prestasi belajar menentukan KPK dan FPB siswa kelas IV A SD.

\section{KESIMPULAN}

Kesimpulan dari studi literatur mengenai pembelajaran kooperatif tipe jigsaw dalam pembelajaran matematika di sekolah dasar adalah pada pembelajaran kooperatif tipe jigsaw terdapat kelompok asal yang heterogen dan kemudian dibentuk kelompok ahli untuk menjadikan siswa-siswa ahli suatu topik yang ditugaskan kemudian saling berbagi informasi kepada teman-teman yang membahas topik berbeda di dalam kelompok asalnya. Berdasarkan kajian terhadap hasil penelitian mengenai pembelajaran kooperatif tipe jigsaw, ditemukan bahwa pembelajaran kooperatif tipe jigsaw mempengaruhi hasil belajar dan prestasi belajar matematika siswa. Kemudian terungkap pula bahwa pembelajaran kooperatif tipe jigsaw dapat meningkatkan hasil belajar dan prestasi belajar matematika siswa.

\section{UCAPAN TERIMA KASIH}

Ucapan terimakasih disampaikan kepada STKIP Singkawang yang telah memfasilitasi penulis dalam menyusun artikel ini. Tidak lupa ucapan terimakasih kepada rekan-rekan yang sudah membantu dalam penyusunan tulisan ini.

\section{DAFTAR PUSTAKA}

[1] Lutfiyah, M., \& Setyawan, A. 2020. Analisis Kemampuan Hasil Belajar Matematika pada Siswa Kelas V Sekolah Dasar Negeri Keleyan 4. Prosiding Nasional Pendidikan: LPPM IKIP PGRI Bojonegoro, 1(1). [Online]. Available: https://prosiding.ikippgribojonegoro.ac.id/index.php/Prosiding/ article/view/1021

[2] Joyce, B., \& Weil, M. Model of teaching. New Jersey: Prentice-Hall, Inc. 1980

[3] Yunus, R. 2020. Peningkatan Hasil Belajar Matematika Melalui Metode Pembelajaran Jigsaw Di Kelas VI SDN 06 Indralaya Utara. Jurnal Ilmiah Bina Edukasi, 13(1), 16-26. [Online]. Available: http://journal.binadarma.ac.id/index.php/jurnalbinaedukasi/arti cle/download/1030/574 
[4] Setiyono, S., Muslim, A., \& Irianto, S. 2020. Peningkatan Hasil Belajar Matematika Materi Pengumpulan Data Melalui Model Pembelajaran Kooperatif Tipe Jigsaw di Kelas V SD Negeri 1 Sidareja. Pendas: Jurnal Ilmiah Pendidikan Dasar, 5(1), 25-37. [Online]. Available: http://dx.doi.org/10.23969/jp.v5i1.2514

[5] Hardini, Isriani dan Dewi Puspitasari. Strategi Pembelajaran Terpadu. Yogyakarta: Familia. 2012.

[6] Laboro, Pertiwi. Peningkatan Hasil Membaca Pemahaman melalui Strategi Pembelajaran Kooperatif (Suatu Penelitian Tindakan di Kelas V Sekolah Dasar Negeri Nomor 90 Kota Gorontalo). Tesis. Jakarta: Universitas Negeri Jakarta. 2010.

[7] Brahim, Theresia K. Pengertian Teori, Model, Pendekatan, Strategi, Metode, Tipe, Teknik, Media, Belajar. Jakarta: Universitas Negeri Jakarta. 2012.

[8] Sharan, Shlomo. Handbook of Cooperative Learning, terjemahan Sigit Prawoto. Yogyakarta: Familia. 2012.

[9] Thoboroni, Muhammad dan Mustofa. Belajar dan Pembelajaran. Jogjakarta: Ar-Ruzz Media. 2010.

[10] Lie, Anita. Cooperative Learning. Jakarta: Grasindo, 2008.

[11] Rusman. Model-Model Pembelajaran Mengembangkan Profesionalisme Guru. Jakarta: Raja Grafindo Persada. 2011.

[12] Suparni, N. (2017). Pengaruh model pembelajaran kooperatif tipe jigsaw terhadap hasil belajar matematika siswa kelas V SD negeri 1 Metro Timur. [Online]. Available: http://digilib.unila.ac.id/id/eprint/26829

[13] Hamna, H., \& BK, Muh Khaerul Ummah. (2017). Pengaruh Pelaksanaan Model Pembelajaran Kooperatif Tipe Jigsaw Terhadap Hasil Belajar Matematika Siswa SD Inpres KassiKassi Kota Makassar. Genta Mulia: Jurnal Ilmiah Pendidikan, 12(1). [Online]. Available: https://ejournal.stkipbbm.ac.id/index.php/gm/article/view/556/ 485

[14] Nurfitriyanti, M. (2017). Pengaruh model pembelajaran kooperatif tipe jigsaw terhadap hasil belajar matematika ditinjau dari kecerdasan emosional. Formatif: Jurnal Ilmiah Pendidikan MIPA, 7(2). [Online]. Available: http://dx.doi.org/10.30998/formatif.v7i2.2229

[15] Handayani, H. (2020). Pengaruh Implementasi Pembelajaran Kooperatif Tipe Jigsaw Terhadap Kemampuan Berpikir Kritis Matematis Siswa Sekolah Dasar. Pendas: Jurnal Ilmiah Pendidikan Dasar, 5(1), 50-60. [Online]. Available: http://dx.doi.org/10.23969/jp.v5i1.1944

[16] Marta, R. (2017). Peningkatan Hasil Belajar Luas Bangun Datar Melalui Model Kooperatif Tipe Jigsaw Bagi Siswa Kelas V Sd Negeri 003 Bangkinang Kota. Jurnal Basicedu, 1(1), 45$54 . \quad$ [Online]. Available: https://doi.org/10.31004/basicedu.v1i1.152

[17] Suryani, L. (2020). Peningkatan Motivasi Belajar Siswa Menghitung Luas Segi Banyak Melalui Strategi Belajar Jigsaw di Kelas VI. Jurnal Pendidikan Tambusai, 4(1), 715-724. [Online]. Available: https://doi.org/10.31004/jptam.v4i1.523

[18] Ragindo, Y. (2020). Peningkatan Hasil Belajar Matematika Konsep Perkalian dan Pembagian Melalui Strategi Pembelajaran Jigsaw. Jurnal Amal Pendidikan, 1(3), 200-206. [Online]. http://dx.doi.org/10.36709/japend.v1i3.11951

[19] Ismayani, L. (2018). Upaya Meningkatkan Hasil Belajar Matematika Bangun Ruang dengan Menggunakan Model Pembelajaran Kooperatif Tipe Jigsaw. Journal of Elementary School (JOES), 1(1), 22-34. [Online]. Available: https://doi.org/10.31539/joes.v1i1.222

[20] Suartini, N. W. (2020). Upaya Meningkatkan Prestasi Belajar Matematika Melalui Model Pembelajaran Kooperatif Jigsaw. [Online]. Available: http://repo.ikippgribali.ac.id/id/eprint/1435
[21] Suryani, S. (2020). Penggunaan Metode Kooperatif Tipe Jigsaw untuk Meningkatkan Prestasi Belajar Matematika Siswa Kelas IV SD Negeri Pajambon. Pedagogi: Jurnal Penelitian Pendidikan, 6(1). [Online]. Available: https://doi.org/10.25134/pedagogi.v6i1.1893 